\title{
Subchronic toxicity study of standardized methanolic extract of Mitragyna speciosa Korth in Sprague-Dawley Rats
}

\section{OPEN ACCESS}

Edited by:

Ashok Kumar,

University of Florida, USA

Reviewed by:

Karthik Bodhinathan

Sanford Burnham Medical Research

Institute, USA

Yogesh Dwivedi,

University of Alabama at Birmingham,

USA

*Correspondence: Jafri Malin Abdullah, Centre for Neuroscience Services and Research, Universiti Sains Malaysia, Jalan Hospital Universiti Sains Malaysia, 16150 Kubang Kerian, Kota Bharu, Kelantan, Malaysia brainsciences@gmail.com

Specialty section:

This article was submitted to

Neuropharmacology,

a section of the journal Frontiers in Neuroscience

Received: 11 January 2015 Accepted: 11 May 2015 Published: 17 June 2015

Citation:

IImie MU, Jaafar H, Mansor SM and Abdullah JM (2015) Subchronic toxicity study of standardized methanolic extract of Mitragyna speciosa Korth in Sprague-Dawley Rats. Front. Neurosci. 9:189.

doi: 10.3389/fnins.2015.00189

\begin{abstract}
Mohd U. Ilmie ${ }^{1}$, Hasnan Jaafar ${ }^{2}$, Sharif M. Mansor ${ }^{3}$ and Jafri M. Abdullah ${ }^{1,4,5 *}$
${ }^{1}$ Department of Neurosciences, School of Medical Sciences, Universiti Sains Malaysia, Kota Bharu, Malaysia, ${ }^{2}$ Department of Pathology, School of Medical Sciences, Universiti Sains Malaysia, Kota Bharu, Malaysia, ${ }^{3}$ Centre for Drug Research, Universiti Sains Malaysia, Georgetown, Malaysia, ${ }^{4}$ Centre for Neuroscience Services and Research, Universiti Sains Malaysia, Jalan Hospital Universiti Sains Malaysia, Kota Bharu, Malaysia, ${ }^{5}$ Hospital Universiti Sains Malaysia, Jalan Hospital Universiti Sains Malaysia, Kota Bharu, Malaysia
\end{abstract}

Mitragyna speciosa Korth, or better known as ketum, has long been used by traditional folk around Southeast Asia to prevent fatigue from working under hot tropical weather and as a replacement of opium, which can then cause addiction. To date, no findings have been reported of the toxic effect of ketum subchronically (28 days). Hence, the aim of this study was to investigate the toxicity of subchronic effect of standardized methanolic extract of ketum (SMEMS) in Sprague-Dawley rats. Rats were orally administered with 100, 200, and $500 \mathrm{mg} / \mathrm{kg}$ of SMEMS for 28 days. Body weights were recorded daily. They were terminated at day 28 to obtain data for hematology, biochemistry, and histopathology of the brain, liver, kidney, lung, heart, sciatic nerve, and spinal cord. The SMEMS affected body weight compared to control group. Biochemistry findings showed that liver and kidney were affected with the abnormal values in AST, creatinine, globulin, glucose, total protein, and urea. However, SMEMS produced toxic effect more to liver, kidney, and lung than other organs as observed histopathologically. The results suggested subchronic exposure of ketum is toxic to the physiology of the animals.

Keywords: standardized methanolic extract, Mitragyna speciosa, subchronic toxicity, oral administration, Sprague-Dawley rats

\section{Introduction}

Mitragyna speciosa Korth, or known as ketum, in Malaysia belongs to Rubiaeceae (Idid et al., 1998), a coffee family. Ketum is an indigenous plant of Thailand and northern penisular Malaysia used traditionally in folk medicine, although it has been reported to cause addiction (Chittrakarn et al., 2008). Ketum has been traditionally used in Malaysia and Thailand as medicinal substance. Originally, local people used it to alleviate pain, coughing, or diarrhea. It is also used to prevent fatigue (Suwanlert, 1975). The leaf has been used in Thailand for its opium-like effect (Burkill et al., 1935). In addition to being used in its own right, it is often used to replace opium when opium is not available.

It was evidenced that mitragynine, the main alkaloid of ketum, at the cellukar level inhibits neurotransmitter release from the nerve endings of vas deferens, partly through the blockade of 
neuronal $\mathrm{Ca}^{2+}$ channels (Matsumoto et al., 2005). It is postulated that neuronal $\mathrm{Ca}^{2+}$ channel-blocking effect of mitragynine is the main mechanism for the analgesic and several other physiological actions of mitragynine. Other action, mitragynine was shown to inhibit forskolin-stimulated cAMP formation in NG108-15 cells in vitro (Tohda et al., 1997). Physiologically, ketum has shown to have antinociceptive, anti-inflammatory, gastrointestinal, and neurophysiological effects (Kumarnsit et al., 2006; Mossadeq et al., 2009; Idayu et al., 2011).

Acute administration of alkaloid extract of ketum significantly resulted in dose-dependent decreases in food and water intake in rats. Furthermore, prolonged suppressing effects were observed following administration of the ketum extract for 60 days and also significantly suppressed weight gaining (Kumarnsit et al., 2006). Standardised methanolic extract of ketum has been reported to increase blood pressure after an hour of administration. High dose of the extract also induced acute severe hepatotoxicity and mild nephrotoxicity. However, the extract has no effect on body weight, food and water consumption, absolute and relative organ weight, and hematology test (Harizal et al., 2010). The present study was designed to determine the toxic effects of standardized methanolic extract of Mitragyna speciosa (SMEMS) in subchronic exposure to the body to add to the information on period-influence exposure to the rodents.

\section{Materials and Methods}

\section{Plant Material}

Leaves of this species were collected from natural sources in Jengka, Pahang, Malaysia. The identification of this species was done by Forest Research Institute Malaysia (FRIM) and kept in Universiti Sains Malaysia (USM) herbarium with voucher number USM 11074. This plant was restricted to research purposes only.

\section{Mitragyna Speciosa Korth Methanolic Extraction and Standardization}

The leaves of the plant were collected and thoroughly washed with distilled water to remove the dirt. The wet leaves were weighed and then dried in an oven at $50^{\circ} \mathrm{C}$ for $12 \mathrm{~h}$. During this time, the leaves were periodically turned over to provide uniform drying. The dried leaves were ground to fine powder by a mill machine and the powder was weighed. Then, $100 \mathrm{~g}$ of the powder was exhaustively soxhlet extracted in methanol $(100 \% \mathrm{v} / \mathrm{v})$ by using an extractor and condenser (Ace Soxhlet Extractor 6730, Condenser 6740, Quick Fit, England) for $4 \mathrm{~h}$ at $60^{\circ} \mathrm{C}$. Next, the extract was concentrated under reduced pressure at $40^{\circ} \mathrm{C}$ using a rotary evaporator. Then, it was further concentrated by allowing it to stand overnight in an oven at $30^{\circ} \mathrm{C}$ to remove any trace of methanol. The final product yielded $20 \mathrm{~g}$ of a dark green extract which was then screened for the presence of the alkaloid mitragynine using GC-MS. The extract produced was standardized with reference to the amount of mitragynine content using validated GC-MS method. Dried extract was stored at $4^{\circ} \mathrm{C}$ until further use (Amresh et al., 2007).

\section{Animals}

Adult male Sprague-Dawley rats were weighing 50-60 g and aged 4 weeks were obtained from the breeding colony of the Animal Research and Service Centre (ARASC) USM. The animals were fed with standard commercial food pellets and water ad libitum. They were housed in a temperature-controlled room at $25 \pm 2{ }^{\circ} \mathrm{C}$ with a relative humidity of $50 \pm 5 \%$ and a $12 \mathrm{~h}$ light $/ 12 \mathrm{~h}$ dark cycle. All the experiments were performed with the approval of Animal Ethics Committee of USM.

\section{Drugs Administration}

SMEMS was suspended in distilled water homogenously to act as a vehicle. Six rats per group were administered with 100 (MS100), 200 (MS200), and 500 (MS500) mg/kg in each group while the control group received distilled water. Rats underwent administration for 28 days daily via oral route (OECD, 2008). Body weight was recorded daily starting from the 1 day administration until the end.

\section{Specimen Collection}

On the last day (day 28), the rats from each group were anesthetised by chloroform, and the blood was taken using cardiac puncture procedure. Some of the blood collected was put in a plastic test tube containing anticoagulant EDTA and some part used for serum collection (biochemical analyses). Then, the rats were decapitated (termination) by guillotine and dissected to obtain brain, lung, heart, kidney, liver, sciatic nerve, and spinal cord for histology purposes.

\section{Biochemical Analysis}

The blood samples that were collected during termination were centrifuged at $3000 \mathrm{rpm}$ for $15 \mathrm{~min}$ to collect the serum. The serum samples then were aspirated off and frozen at $-80^{\circ} \mathrm{C}$. They were analyzed for the determination of albumin, alanine aminotransferase (ALT), aspartate aminotransferase (AST), cholesterol, creatinine, glucose, phosphate, globulin, urea, total protein, and lactate dehydrogenase (LDH). Biochemical analyses were carried out with an automatic chemistry analyser (Hitachi 902, Japan; Reagent by ROCHE Diagnostic GmbH, Germany).

\section{Haematology}

The blood samples that were collected underwent blood count using the automatic hematology system (BC-3000 Plus, Mindray, Shenzhen, China) to evaluate red blood cell (RBC), white blood cell (WBC), hemoglobin (HGB), haematocrit (HCT), mean corpuscular volume (MCV), mean corpuscular hemoglobin $(\mathrm{MCH})$, mean corpuscular hemoglobin concentration (MCHC), and platelet (PLT).

\section{Histopathology \\ Tissue Preparation}

The method of tissue preparation was adapted from Jain et al. (2008). The tissues obtained during the termination process were fixed in 10\% formalin, dehydrated in gradual ethanol (50-100\%). After that, the tissues were cleared using xylene and embedded in paraffin. The process continued with the sectioning process. All tissues were sectioned with $5 \mu \mathrm{m}$ of thickness using microtome 
and transferred into a $40^{\circ} \mathrm{C}$ water bath for fishing process. The sections were fished by glass slides and then allowed to dry on the slide warmer.

\section{Haematoxylin and Eosin (H\&E) Staining}

The H\&E staining protocol followed a standard protocol of the Department of Pathology, USM. The staining process was started by soaking the sections in xylene twice for $2 \mathrm{~min}$ each. The process continued by soaking in absolute alcohol, $90 \%$ and $80 \%$ alcohol for $2 \mathrm{~min}$ each. Then, the slides were rinsed with tap water and were soaked in haematoxylin for $20 \mathrm{~min}$. After that, the slides were rinsed again under running tap water. Then, they were dipped in acid alcohol for $3 \mathrm{~s}$ and were rinsed again for $5 \mathrm{~min}$ under tap water. Next, the slides were dipped in ammonia water for $10 \mathrm{~s}$ and rinsed for $2 \mathrm{~min}$. The slides were then soaked in eosin for $2 \mathrm{~min}$. The process continued by soaking the slides in $80,90 \%$, and absolute alcohol for $2 \mathrm{~min}$ each. The last step was soaking the slides in xylene twice for $2 \mathrm{~min}$ each. The sections were covered by cover slip and observed under microscope.

\section{Statistical Analyses}

Statistical analysis for body weight data was done by repeated measure ANOVA while Tukey's test was used for the posthoc test. For hematology and biochemical analysis, data were analyzed using One-Way ANOVA. Differences between groups were considered significant if $p<0.05$. All data points show the mean of standard error means (SEM).

\section{Results}

\section{Body Weight Measurement}

Subchronic exposure of SMEMS showed average body weight gains for MS100, MS200, and MS500 were 6.6, 7.9, and $5.2 \mathrm{~g} /$ day, respectively, compared to control of $7.8 \mathrm{~g} /$ day. MS500 showed the lowest weight gain compared to other dose regime groups and also the control group. There were significant differences between MS200 and other groups $(p<0.01$, except for MS500 which $p<0.001)$.

\section{Biochemical Analyses}

Biochemistry data in Table 1 some of the parameters such as AST, creatinine, globulin, glucose, total protein, and urea showed significant differences when compared to respective group. Group MS100 differed significantly when compared to control group with $p<0.05$ for AST. MS500 recorded significantly lower than MS100 for AST parameter. MS 200 and MS500 recorded significant differences in creatinine reading compared to the control group with $p<0.05$ and $p<0.01$, respectively. Among the groups, only MS200 recorded significantly high globulin readings compared to the control group with $p<0.05$. In glucose, MS200 and MS500 were significantly higher than in the control group with $p<0.05$. Total protein reading in MS200 was significantly higher than the control with $p<0.05$. Lastly, both MS200 and MS500 showed significant differences in urea parameter when compared to both control and MS100 groups.

\section{Haematology}

Haematology results show that none of the groups differ significantly when compared to control for all parameters. Data presented were analyzed by using One-Way ANOVA test. The details are shown in Table 2.

\section{Histopathology}

Histopathology results showed that brain, heart, spinal cord, and sciatic nerve were not affected by the subchronic exposure to SMEMS for all the doses when compared to normal. There were no abnormalities observed in the histopathology slides. However, the other organs such as liver, lung, and kidney were affected by SMEMS, as shown in Figure 1. Doses of 200 and $500 \mathrm{mg} / \mathrm{kg}$ affected kidney, liver, and lung significantly compared to the lowest dose and the vehicle group.

\section{Discussion}

M. speciosa has long been used in treating illnesses traditionally. The present study has been conducted to gather information on the toxic effects of the subchronic consumption of the plant. Animals were exposed to SMEMS for 28 days via oral route. Throughout the administrations, daily body weight measurements were taken. On day 28, animals were euthanised to obtain blood and organs for biochemistry, hematology, and histopathology analyses. Dosages were justified based on previous study by Reanmongkol et al. (2007) that proved dose $100 \mathrm{mg} / \mathrm{kg}$ methanolic extract of ketum showed significant effect toward nociceptive response acutely. Thus, in this subchronic study we tested the same dose and increased to 200 and $500 \mathrm{mg} / \mathrm{kg}$.

Animals in the group MS100 and MS500 showed significant body weight loss compared to the control group, while MS200 showed similarity in body weight gain compared to the control group. Kumarnsit et al. (2006) reported that ketum extract suppressed weight gain after 60 days of administration. Chittrakarn et al. (2008) documented ketum extract decreased the increment of body weight at doses of 200 and $400 \mathrm{mg} / \mathrm{kg}$ after 30 days of exposure. Mitragynine, the main biocompound of ketum, exerted an inhibitory effect on gastric acid secretion through opioid receptors. There is a probability that the mechanism of side effects such as anorexia and weight loss induced by mitragynine is related to the inhibitory effect on gastric acid secretion (Tsuchiya et al., 2002). Sabetghadam et al. (2013) reported a significant increase in the relative body weight of male rats treated with 28 -day $1 \mathrm{mg} / \mathrm{kg}$ mitragynine. However, female rats treated with 28 days $100 \mathrm{mg} / \mathrm{kg}$ mitragynine recorded body weight decrease. Thus, high dose of ketum extract might affect the appetite at subchronic exposure.

This study also investigated biochemical analysis of the serum. Liver-related biochemicals such as AST, total bilirubin, and glucose in the present study showed statistically significant differences when compared to the control group. Our findings showed that the AST reading was significantly lower in rats that received the highest dose of ketum compared to rats that received the lowest dose of ketum. Significant differences were also observed between MS100 and control group. AST is 
TABLE 1 | Biochemistry data of rats after subchronic administrations of SMEMS.

\begin{tabular}{|c|c|c|c|c|}
\hline Parameter & Control $(n=6)$ & MS100 $(n=6)$ & MS200 $(n=6)$ & MS500 $(n=6)$ \\
\hline Albumin (g/l) & $33.67 \pm 0.422$ & $34.50 \pm 0.671$ & $36.83 \pm 1.302$ & $35.50 \pm 0.563$ \\
\hline ALT (IU/L) & $56.00 \pm 1.862$ & $85.33 \pm 17.653$ & $72.40 \pm 7.325$ & $61.00 \pm 2.683$ \\
\hline AST (IU/L) & $156.33 \pm 10.607$ & $303.50 \pm 55.438^{\#}$ & $215.80 \pm 19.368$ & $100.50 \pm 4.080^{\varnothing \varnothing}$ \\
\hline Cholesterol (mmol/l) & $1.61 \pm 0.045$ & $1.59 \pm 1.10 \mathrm{~g}$ & $1.51 \pm 0.132$ & $1.46 \pm 0.948$ \\
\hline Creatinine $(\mu \mathrm{mol} / L)$ & $49.50 \pm 0.619$ & $58.83 \pm 1.108$ & $63.17 \pm 4.629^{\#}$ & $65.00 \pm 3.493^{\# \#}$ \\
\hline Globulin (g/L) & $30.50 \pm 1.285$ & $32.50 \pm 1.177$ & $40.17 \pm 4.254^{\#}$ & $35.50 \pm 1.057$ \\
\hline Glucose (mmol/l) & $6.52 \pm 0.294$ & $7.47 \pm 0.306$ & $8.37 \pm 0.390^{\#}$ & $8.20 \pm 0.218^{\#}$ \\
\hline Phosphate (mmol/l) & $2.56 \pm 0.058$ & $2.72 \pm 0.092$ & $2.87 \pm 0.075$ & $2.67 \pm 0.081$ \\
\hline LDH (mmol/l) & $2471.67 \pm 389.186$ & $2189.33 \pm 431.132$ & $2587.20 \pm 242.563$ & $2650.83 \pm 325.367$ \\
\hline T. Protein (g/l) & $64.17 \pm 1.046$ & $67.00 \pm 1.366$ & $77.00 \pm 5.532^{\#}$ & $69.60 \pm 1.033$ \\
\hline Urea (mmol/l) & $6.967 \pm 0.150$ & $7.60 \pm 0.348$ & $9.23 \pm 0.504^{\# \varnothing}$ & $9.30 \pm 0.480^{\# \varnothing}$ \\
\hline
\end{tabular}

Data indicate mean \pm SEM

$A L T$, alanine aminotransferase; AST, aspartate aminotransferase; $L D H$, lactate dehydrogenase.

\# Statistically significant different compared to control, $p<0.05$;

\#\# Statistically significant different compared to control, $p<0.01$;

$\varnothing$ Statistically significant different compared to MS100, $p<0.05$;

$\varnothing \varnothing$ Statistically significant different compared to MS100, $p<0.01$.

TABLE 2 | Haematology data of rats after subchronic administration of SMMSE.

\begin{tabular}{|c|c|c|c|c|}
\hline Parameter & Control $(n=6)$ & MS100 $(n=6)$ & MS200 $(n=6)$ & MS500 $(n=6)$ \\
\hline White Blood Cell (× 109/L) & $6.70 \pm 0.071$ & $7.23 \pm 0.680$ & $6.44 \pm 0.745$ & $6.03 \pm 1.492$ \\
\hline Haemoglobin (g/L) & $14.34 \pm 0.300$ & $14.55 \pm 0.393$ & $15.38 \pm 0.421$ & $15.43 \pm 0.259$ \\
\hline Red Blood Cell (× 10 $12 / L)$ & $7.35 \pm 0.140$ & $7.36 \pm 0.396$ & $7.72 \pm 0.336$ & $7.62 \pm 0.230$ \\
\hline Haematocrit (L/L) & $40.48 \pm 0.876$ & $40.86 \pm 1.228$ & $43.06 \pm 1.421$ & $43.05 \pm 0.620$ \\
\hline MCV (fL) & $55.24 \pm 1.490$ & $55.93 \pm 1.375$ & $55.90 \pm 0.719$ & $56.78 \pm 1.975$ \\
\hline $\mathrm{MCH}(\mathrm{g} / \mathrm{L})$ & $19.48 \pm 0.517$ & $19.85 \pm 0.552$ & $19.92 \pm 0.332$ & $20.23 \pm 0.453$ \\
\hline $\mathrm{MCHC}(\mathrm{g} / \mathrm{L})$ & $35.38 \pm 0.287$ & $35.58 \pm 0.125$ & $35.70 \pm 0.190$ & $35.80 \pm 0.549$ \\
\hline Platelet (× $\left.10^{9} / \mathrm{L}\right)$ & $728.00 \pm 70.379$ & $907.00 \pm 6.285$ & $829.00 \pm 46.242$ & $850.50 \pm 49.769$ \\
\hline
\end{tabular}

Data indicate mean \pm SEM.

MCV, mean corpuscular volume; $\mathrm{MCH}$, mean corpuscular hemoglobin; MCHC, mean corpuscular hemoglobin concentration.

one of the transaminases that are useful in evaluating muscle and liver damage in small and large animals. Its levels are expected to be less in the state of necrosis, as observed in the histopathology part of the present study. The findings showed that the level of creatinine in the groups MS200 and MS500 were higher significantly compared to that of the control group. Data from an acute toxicity study of ketum (dose of $1000 \mathrm{mg} / \mathrm{kg}$ ) showed similar findings to the present study (Harizal et al., 2010). This biochemistry data was paralleled to our finding of kidney histopathology discussed below. The increase in serum creatinine demonstrates that the filtration process of the kidneys is deficient. Opioids such as morphine have been reported to cause renal damage by increasing the creatinine level (Atici et al., 2005). Another indicator of renal damage is the increase in the blood urea parameter. In the present study, the data show a high level of blood urea in MS200 and MS500 groups compared to that of control and MS100 groups. The findings also showed similarity to the acute toxicity study of ketum in Sprague-Dawley rats (Harizal et al., 2010) and rats treated with morphine chronically (Atici et al., 2005). Thus, M. speciosa, which possesses an opioid-like effect, is believed through chronic exposure to impair renal function or cause nephrotoxicity. Globulin was observed to be high in rats receiving $200 \mathrm{mg} / \mathrm{kg}$ ketum differed significantly from control. Globulins are important plasma proteins primarily associated with antibodies. Mitragynine showed significant increases in LDH, ALT, AST, and urea after being treated daily for 28 days with a subchronic dose of $100 \mathrm{mg} / \mathrm{kg}$ (Sabetghadam et al., 2013). This shows that the extract is toxic to the blood and might trigger the immune system to react toward that toxicity.

Subchronic administration of SMEMS not only caused damage to the liver as occurred in the acute toxicity studies of ketum from the histopathological data (Harizal et al., 2010; Kamal et al., 2012), but also caused damage to kidneys and lungs. At all doses, M. speciosa showed toxic effects for liver, kidneys and lungs. The observation by H\&E staining showed the presence of blood vessels and neutrophils in MS500, portal inflammation, interphase necrosis, and bile duct proliferation in MS200 in the liver. Rats treated with chronic morphine suffered liver damage caused by focal vacuolar (fatty changes) degenerative change, with mononuclear cell infiltration in the hepatocytes (Sumathi and Niranjali Devaraj, 2009). Mild congestion of kidney blood vessels was also observed in MS100 and MS200. However, blood vessel congestion was nearly moderate in MS500. 


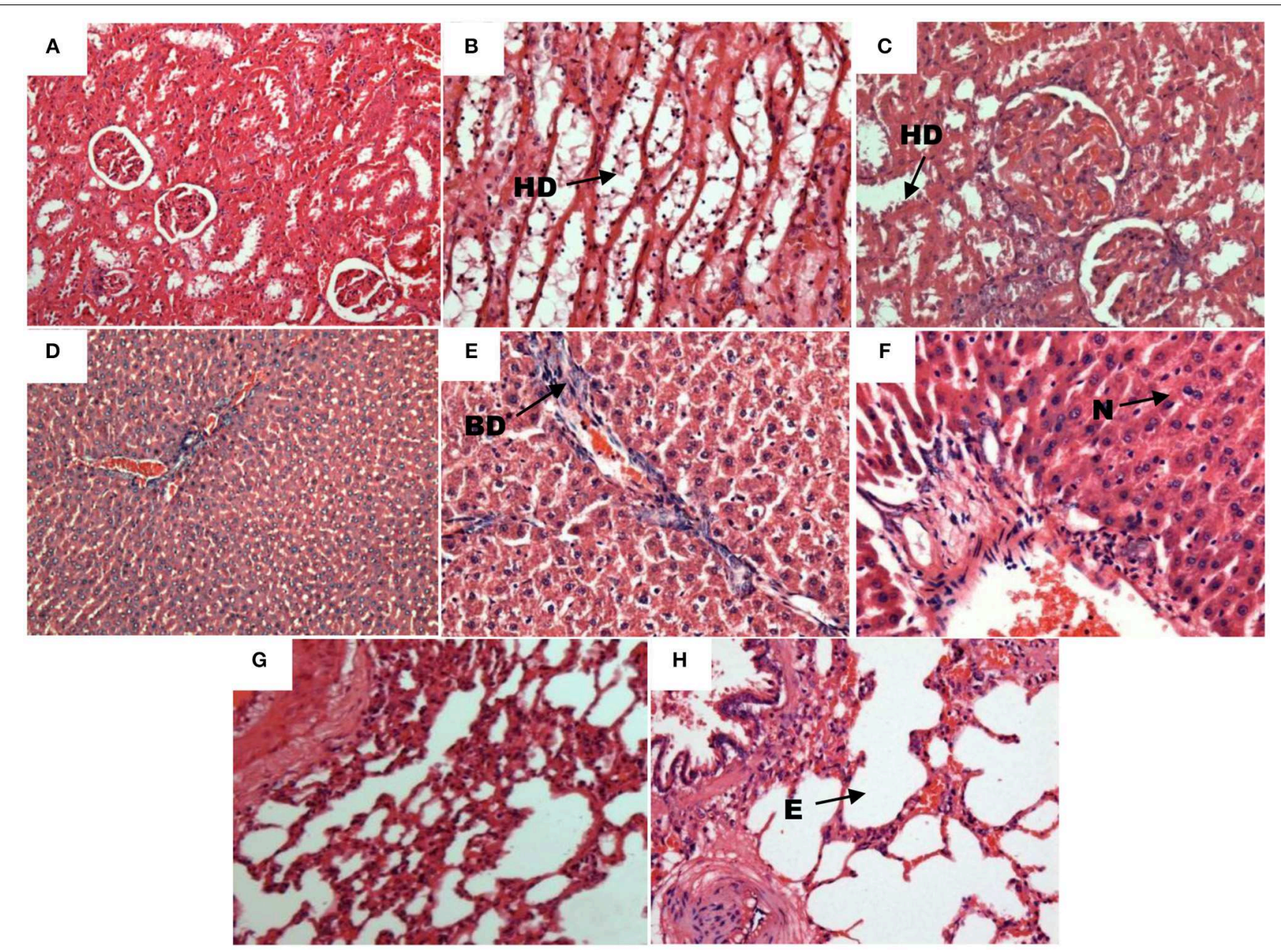

FIGURE 1 | Histopathology slides of affected organs after subchronic exposure to SMEMS. (A) Kidney section from control (10X). (B) Hydropic degeneration present at the kidney's cortex of MS200 (20X). (C) Hydropic degeneration (HD) present at the kidney's medulla of MS500 (20X). (D) Liver section from control (10X). (E) Section of liver showing bile duct proliferation BD (20X). (F) Section of liver showing the presence of neurtrophil (N) from exposed group (20X). (G) Lung section from control (20X). (H) Section of lung showing emphysema (20X).
Hydropic degeneration was seen in the medulla and cortex regions of the kidney for MS100 and MS200, respectively. In MS500, hydropic degeneration was seen in both medulla and cortex regions. The effect of chronic morphine intoxication on rat kidneys showed mild tubular epithelial cell degeneration with cellular casts within the lumen of the tubules (Sumathi and Niranjali Devaraj, 2009). These effects of ketum extract on liver and kidney were similar to the effects of morphine (Atici et al., 2005). SMEMS exposed subchronically affected lungs by causing emphysema and the over-inflation of the alveoli. We believed that chemicals from the extract trapped in the alveoli later caused the inflammatory response, which will cause the alveolar septum to disintegrate known as septal rupture. Septal rupture leads to significant deformations of lung architecture (Nazari, 2002). Our unpublished data showed that SMEMS had fully blocked the long-term potentiation(LTP) in the same group of rat's hippocampal slices after subchronic exposure despite histopathology findings of the brain that did not show any apparent morphological changes. Li et al. (2012) reported that, long-term potentiation was impaired in xCT-deficient sut mice although no morphological changes were observed in the brain specimens stained with $\mathrm{H} \& \mathrm{E}$ and examined under the electron microscope. We speculate that the dosages applied in our experiments were insufficient to cause morphological alterations in the brain despite exhibiting changes in LTP.

In several parameters, the middle dose which is $200 \mathrm{mg} / \mathrm{kg}$ showed whether it was the highest or the lowest in giving such effects to certain results. This phenomenon can be explained as the hormetic response or U-shaped response. The hormetic response would reflect a decrease in the incidence of an adverse response such as disease/injury at low dose and an increase at higher dose (Calabrese and Baldwin, 2001).

\section{Conclusion}

In conclusion, $M$. speciosa Korth is toxic to the rat upon subchronic exposure of 28 days. This toxicity can affect body weight, behavior, organs such as liver, kidney and 
lung and the blood. Generally, the higher doses in both MS200 and MS500 affected most of the parameters. Data from biochemical analyses and histopathology support each other and demonstrate that the plant is such an intoxicant material. The present study provides information primarily on whole-body toxicity effects at the subchronic level. Further study should be undertaken to seek the effect of chronic

\section{References}

Amresh, G., Singh, P. N., and Rao, C. H. V. (2007). Antinociceptive and antiarthritic activity of Cissampelos paraira roots. J. Ethnopharmacol. 111, 531-536. doi: 10.1016/j.jep.2006.12.026

Atici, S., Cinel, I., Cinel, L., Doruk, N., Eskandari, G., and Oral, U. (2005). Liver and kidney toxicity in chronic use of opioids: an experimental long term treatment model. J. Biosci. 30, 245-252. doi: 10.1007/BF02703705

Burkill, I. H., Birtwistle, W., Foxworthy, F. W., Scrivenor, J. B., and Watson, J. G. (1935). A Dictionary of the Economic Products of the Malay Peninsula, London: Published on behalf of the governments of the Straits settlements and Federated Malay states by the Crown agents for the colonies.

Calabrese, E. J., and Baldwin, L. A. (2001). U-shaped Dose-responses in biology, toxicology, and public health 1. Annu. Rev. Public Health 22, 15-33. doi: 10.1146/annurev.publhealth.22.1.15

Chittrakarn, S., Sawangjaroen, K., Prasettho, S., Janchawee, B., and Keawpradub, N. (2008). Inhibitory effects of kratom leaf extract (Mitragyna speciosa Korth.) on the rat gastrointestinal tract. J. Ethnopharmacol. 116, 173-178. doi: 10.1016/j.jep.2007.11.032

Harizal, S., Mansor, S., Hasnan, J., Tharakan, J., and Abdullah, J. (2010). Acute toxicity study of the standardized methanolic extract of Mitragyna speciosa Korth in rodent. J. Ethnopharmacol. 131, 404-409. doi: 10.1016/j.jep.2010.07.013

Idayu, N. F., Hidayat, M. T., Moklas, M., Sharida, F., Raudzah, A. N., Shamima, A., et al. (2011). Antidepressant-like effect of mitragynine isolated from Mitragyna speciosa Korth in mice model of depression. Phytomedicine 18, 402-407. doi: 10.1016/j.phymed.2010.08.011

Idid, S., Saad, L., Yaacob, H., and Shahimi, M. (1998). Evaluation of analgesia induced by mitragynine, morphine and paracetamol on mice. ASEAN Rev. Biodivers. Environ. Conserv. Article 4, 1-7.

Jain, A., Soni, M., Deb, L., Rout, S., Gupta, V., and Krishna, K. (2008). Antioxidant and hepatoprotective activity of ethanolic and aqueous extracts of Momordica dioica Roxb. leaves. J. Ethnopharmacol. 115, 61-66. doi: 10.1016/j.jep.2007.09.009

Kamal, M. S. A., Ghazali, A. R., Yahya, N. A., Wasiman, M. I., and Ismail, Z. (2012). Acute Toxicity Study of Standardized Mitragyna speciosa Korth Aqueous Extract in Sprague Dawley Rats. J. Plant Stud. 1, 120. doi: 10.5539/jps.v1n2p120

Kumarnsit, E., Keawpradub, N., and Nuankaew, W. (2006). Acute and long-term effects of alkaloid extract of Mitragyna speciosa on food and water intake and body weight in rats. Fitoterapia 77, 339-345. doi: 10.1016/j.fitote.2006.04.006

Li, Y., Tan, Z., Li, Z., Sun, Z., Duan, S., and Li, W. (2012). Impaired long-term potentiation and long-term memory deficits in xCT-deficient sut mice. Biosci. Rep. 32, 315-321. doi: 10.1042/BSR20110107 exposure to this plant in order to understand its potential for human use.

\section{Acknowledgments}

This is to acknowledge a short-term grant from the School of Medical Sciences, Universiti Sains Malaysia (304/PPSP/6131429).

Matsumoto, K., Yamamoto, L. T., Watanabe, K., Yano, S., Shan, J., Pang, P. K. T., et al. (2005). Inhibitory effect of mitragynine, an analgesic alkaloid from Thai herbal medicine, on neurogenic contraction of the vas deferens. Life Sci. 78, 187-194. doi: 10.1016/j.lfs.2005.04.042

Mossadeq, W. S., Sulaiman, M., Mohamad, T. T., Chiong, H., Zakaria, Z., Jabit, M., et al. (2009). Anti-inflammatory and antinociceptive effects of Mitragyna speciosa Korth methanolic extract. Med. Princi. Pract. 18, 378-384. doi: $10.1159 / 000226292$

Nazari, S. (2002). Mechanical events in physiopathology of idiopathic pulmonary emphysema: a theoretical analysis. Internet J. Thorac. Cardiovasc. Surg. 5.

OECD. (2008). "Repeated Dose 28-day oral toxicity study in Rodents" in OECD Guidelines for the Testing of Chemicals, Section 4 (Pairs: OECD Publishing). doi: 10.1787/9789264070684-en

Reanmongkol, W., Keawpradub, N., and Sawangjaroen, K. (2007). Effects of the extracts from Mitragyna speciosa Korth. leaves on analgesic and behavioral activities in experimental animals. Songklanakarin J. Sci. Technol. 29(Suppl. 1), 39-48.

Sabetghadam, A., Ramanathan, S., Sasidharan, S., and Mansor, S. M. (2013). Subchronic exposure to mitragynine, the principal alkaloid of Mitragyna Speciosa, in rats. J. Ethnopharmacol. 146, 815-823. doi: 10.1016/j.jep.2013.02.008

Sumathi, T., and Niranjali Devaraj, S. (2009). Effect of Bacopa monniera on liver and kidney toxicity in chronic use of opioids. Phytomedicine 16, 897. doi: 10.1016/j.phymed.2009.03.005

Suwanlert, S. (1975). A study of kratom eaters in Thailand. Bull. Narc. 27, 21-27.

Tohda, M., Thongpraditchote, S., Matsumoto, K., Murakami, Y., Sakai, S.-I., Aimi, N., et al. (1997). Effects of mitragynine on cAMP formation mediated by delta-opiate receptors in NG108-15 cells. Biol. Pharm. Bull. 20, 338-340.

Tsuchiya, S., Miyashita, S., Yamamoto, M., Horie, S., Sakai, S. I., Aimi, N., et al. (2002). Effect of mitragynine, derived from Thai folk medicine, on gastric acid secretion through opioid receptor in anesthetized rats. Eur. J. Pharmacol. 443, 185-188. doi: 10.1016/S0014-2999(02)01588-1

Conflict of Interest Statement: The authors declare that the research was conducted in the absence of any commercial or financial relationships that could be construed as a potential conflict of interest.

Copyright (C) 2015 Ilmie, Jaafar, Mansor and Abdullah. This is an open-access article distributed under the terms of the Creative Commons Attribution License (CC BY). The use, distribution or reproduction in other forums is permitted, provided the original author(s) or licensor are credited and that the original publication in this journal is cited, in accordance with accepted academic practice. No use, distribution or reproduction is permitted which does not comply with these terms. 